\title{
Wear Analysis on 410 Stainless Steel Material by Hardening Process
}

\author{
Dr. Ram Subbiah ${ }^{1}$, M. Harini ${ }^{2}$, M. Maneesha ${ }^{3}$, Md. Jahangeer ${ }^{4}$, Dr. R. Rajavel ${ }^{5}$ \\ ${ }^{1}$ Associate Professor, Mechanical Engineering, GRIET, Hyderabad \\ 2, 3,4 B.Tech - Mechanical Engineering, GRIET, Hyderabad \\ ${ }^{5}$ Professor \& Head, Mechanical Engineering, AMET University, Chennai
}

\begin{abstract}
The wear conduct of 410 stainless steel has been examined under a dry sliding contact at consistent load. It was found that hardening procedure was successful in enhancing the wear conduct of stainless steel material, advancing the property of pliability. A low temperature hardening has been completed for three distinct examples at a hour, a hour and a half, 120 minutes. Untreated stainless steel was utilized as a kind of perspective material and experienced wear test for comparison with different hardening samples. The hardening samples uncover that hard layers that are shaped which enhances the surface hardness. Small scale hardness estimations uncovered a critical increment in hardness after treatment. The layers were portrayed by optical magnifying lens and checking electron magnifying lens investigation.
\end{abstract}

Keywords - Hardening, stainless steel, wear, hardness.

\section{INTRODUCTION}

Hardening is done to get high surface hardness, increment wear resistance, enhance exhaustion life, and enhance consumption resistance, high dimensional solidness. Stainless steel is utilized in view of their high imperviousness to oxidation and consumption resistance. They discover applications broadly utilized as a part of atomic reactors, car parts like cam shafts, cam adherents, injectors, bio restorative inserts, synthetic and nourishment ventures. Of the different warmth treatment methods accessible, hardening offers the advantages of high dimensional strength. The elevated amounts of substrate add to incredible consumption resistance in stainless steel materials.

Decided for this exploration work, on the premise of their application and business accessibility, hardening produces more uniform metallurgical framed case profundity. The profundity and nature of case would be controlled by the synthetic arrangement under which extinguishing is finished. Solidifying is completed by taking steel to austenizing temperature and extinguishing it all of a sudden.
The case solidifying medium utilized as a part of this strategy is oil extinguishing.

\section{MATERIALS USED}

The material used in the present work was 410 stainless steel material. The specimens were prepared in following forms. (i) Polished cylindrical disc specimen measuring 50 $\mathrm{mm}$ diameter and $10 \mathrm{~mm}$ height were used. (ii) Pin specimen with diameter $8 \mathrm{~mm}$ and height $30 \mathrm{~mm}$ were used with taper edged surface.

\section{TREATMENTS}

Prior to all treatments, the specimens were cleaned ultrasonically, rinsed and dried, with care taken to avoid finger contact. Before hardening, the specimens were sand blasted, pickled in $15 \%$ sulphuric acid for 20 minutes. The samples were degreased using acetone and preheated in an air circulated furnace for 15 minutes. The samples were hardened for three different temperatures at 60 minutes, 90 minutes, 120 minutes respectively.

\section{WEAR MEASUREMENTS}

Wear tests were carried out on a pin on disc machine. A stationery pin was mounted horizontally against a vertically rotating disc. The disc is rotated at a constant speed of 1000 rpm at a constant load of $2 \mathrm{Kg}$, which was applied continuously for a fixed period of 2 minutes under dry conditions. Wear test were conducted and the samples were replaced one by one. The weights of the specimens were measured using a standard caliberometer. The difference between the specimen before and after testing gives the wear loss.

\section{RESULTS AND DISCUSSIONS}

The hardened specimen results were compared with the untreated specimen and it was found that, in hardened specimen, the mixture of cementite and ferrite were precipitated on the surface, to improve the hardness of material. The wear rate of untreated specimen is specified to 
be lower that of hardened material. Hence good surface hardness is obtained. Low temperature hardening results in good wear performance to relative case depth, which improves wear resistance. The ductility of material is promoted in 410 stainless steel material. So by the process of re - heat treatment of 410 stainless steel material, this material can also be used for higher applications like power plant turbine blades, nuclear reactors, marine applications where components are subjected to sea water, automobile applications.

\subsection{Optical Microscope Results}

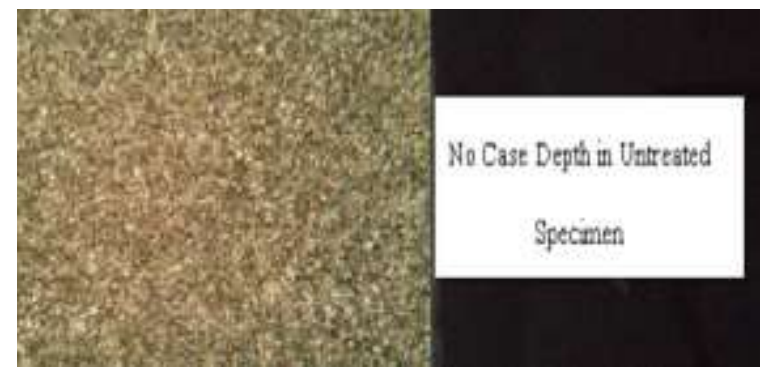

Fig.1: Untreated Specimen

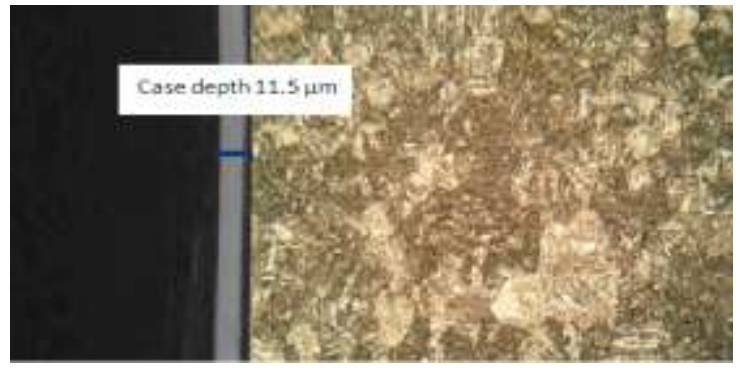

Fig.2: Hardening for 1 hour 11.5 microns

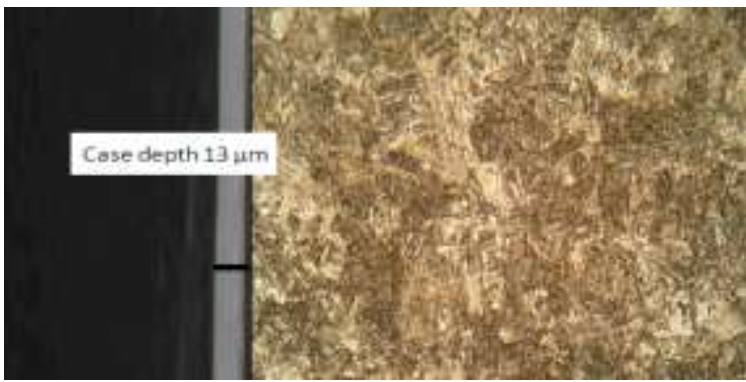

Fig.3: Hardening for 1.5 hour 13 microns

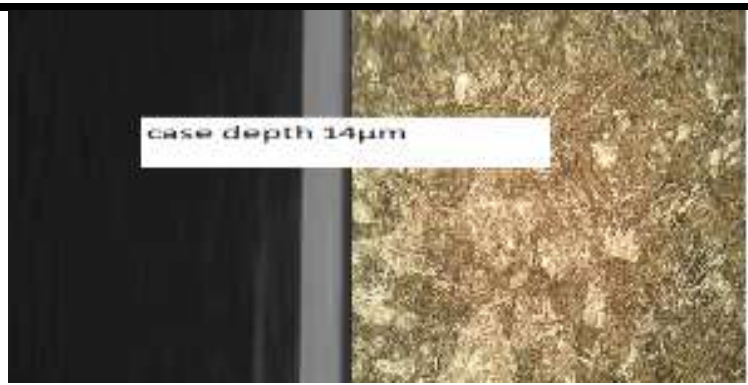

Fig.4: Hardening for 2 hour 14 microns

From the figure $1,2,3,4$ it is seen that, as the time of hardening increases, case depth also increases. Therefore the case depth is increased from 11.5 to 14 microns specimens respectively. The results are compared with untreated specimen. Hence hardened specimen done for 120 minutes improves its wear resistance causing low wear loss and wear rate.

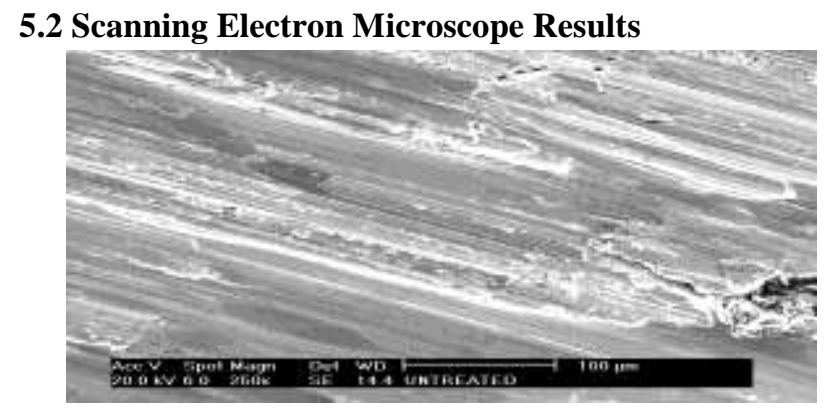

Fig.5: Untreated Specimen SEM Image

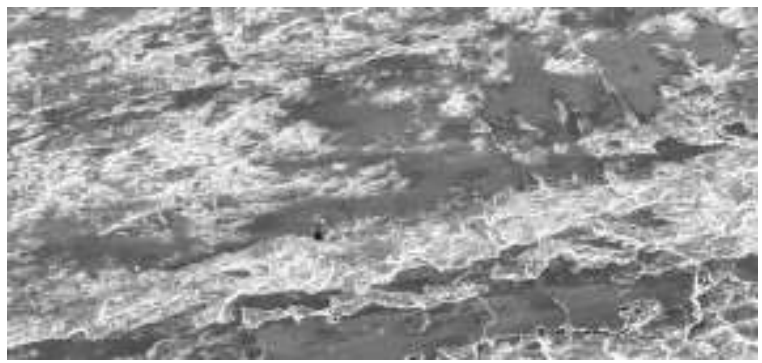

Fig.6: SEM Image for 1 hour hardened specimen

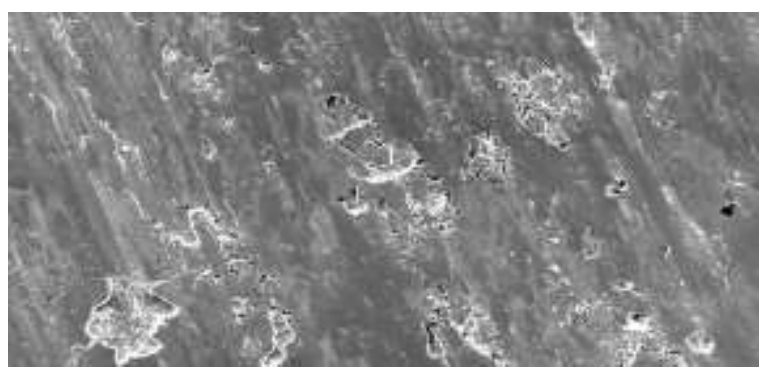

Fig.7: SEM Image for 1.5 hour hardened specimen 


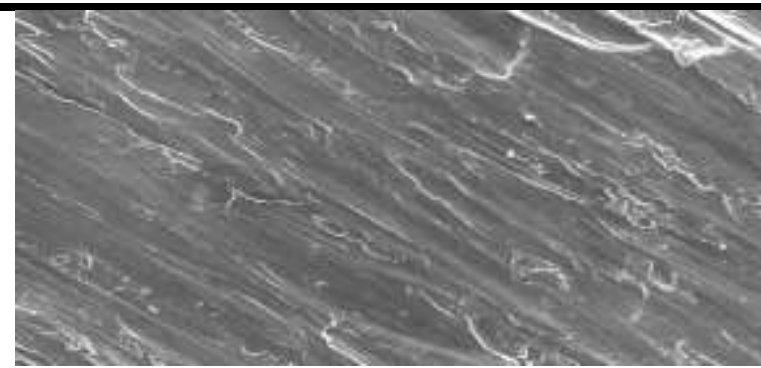

Fig.8: SEM Image for 2 hour hardened specimen

From the figure 5,6,7,8 the specimens were compared with untreated specimen. The peel of material is very high in untreated specimen. The wear of material is high. As the case depth increases, wear loss of the material decreases. In hardened specimen for 120 minutes, the wear loss of material is less when compared to other hardened specimens, which improves its wear resistance.

\section{CONCLUSION}

The result of this work confirms that, hardening process has effectively improved its wear resistance. As the time for treatment increases, the case depth also increases. From the wear studies, it is observed that hardened specimen for 120 minutes has a very good wear resistance. It is showed that, as the time of treatment increases, weight loss decreases, hence the life of the material is increased.

\section{REFERENCES}

[1] M.K. Lee, G.H. Kim, K.H. Kim, W.W. Kim, "Effects of the surface temperature and cooling rate on the residual stresses in a flame hardening of $12 \mathrm{Cr}$ steel" Journal of Materials Processing Technology, Volume 176, Issues 1-3, 6 June 2006, Pages 140-145

[2] M.K. Lee, G.H. Kim, K.H. Kim, W.W. Kim, "Control of surface hardnesses, hardening depths, and residual stresses of low carbon $12 \mathrm{Cr}$ steel by flame hardening" Surface and Coatings Technology, Volume 184, Issues 2-3, 22 June 2004, Pages 239-246

[3] C.F. Kuang, J. Li, S.G. Zhang, J. Wang, H.F. Liu, A.A. Volinsky, "Effects of quenching and tempering on the microstructure and bake hardening behavior of ferrite and dual phase steels" Materials Science and Engineering: A, Volume 613, 8 September 2014, Pages 178-183.
[4] Lipeng Ding, Yaoyao Weng, Sainan Wu, Robert E. Sanders, Zhihong Jia, Qing Liu, "Influence of interrupted quenching and pre-aging on the bake hardening of $\mathrm{Al}-\mathrm{Mg}-\mathrm{Si}$ Alloy" Materials Science and Engineering: A, Volume 651, 10 January 2016, Pages 991-998

[5] K.O. Findley, J. Hidalgo, R.M. Huizenga, M.J. Santofimia, "Controlling the work hardening of martensite to increase the strength/ductility balance in quenched and partitioned" Materials \& Design, Volume 117, 5 March 2017, Pages 248-256

[6] Jun Zhang, Hua Ding, R.D.K. Misra, Chao Wang, "Enhanced stability of retained austenite and consequent work hardening rate through prequenching prior to quenching and partitioning in a Q$P$ microalloyed steel" Materials Science and Engineering: A, Volume 611, 12 August 2014, Pages 252-256

[7] Jun Zhang, Hua Ding, R.D.K. Misra, "Enhanced strain hardening and microstructural characterization in a low carbon quenching and partitioning steel with partial austenization" Materials Science and Engineering: A, Volume 636, 11 June 2015, Pages 5359.

[8] Ji Dong, Xiaosheng Zhou, Yongchang Liu, Chong Li, Chenxi Liu, Huijun Li, "Effects of quenchingpartitioning-tempering treatment on microstructure and mechanical performance of $\mathrm{Nb}-\mathrm{V}$-Ti microalloyed ultra-high strength steel" Materials Science and Engineering: A, Volume 690, 6 April 2017, Pages 283-293

[9] Qingguo Hao, Shengwei Qin, Yu Liu, Xunwei Zuo, Nailu Chen, Yonghua Rong, "Relation between microstructure and formability of quenchingpartitioning-tempering martensitic steel" Materials Science and Engineering: A, Volume 671, 1 August 2016, Pages 135-146

[10] H. Rastegari, A. Kermanpur, A. Najafizadeh, "Effect of initial microstructure on the work hardening behavior of plain eutectoid steel" Materials Science and Engineering: A, Volume 632, 24 April 2015, Pages 103-109. 